\title{
Evaluating Anti-Inflammatory Potential of Etodolac Co-Crystals: Nitric Oxide, IL-6 And TNF-a As Potential Markers
}

\section{Poonam Parashar}

Babasaheb Bhimrao Ambedkar University

\section{Shalini Gautam}

Babasaheb Bhimrao Ambedkar University

Neelu Singh

Babasaheb Bhimrao Ambedkar University

Jovita Kanoujia

Amity University

Abhishek Yadav

Babasaheb Bhimrao Ambedkar University

Indu Singh

Amity University

\section{Monika Dwivedi}

Babasaheb Bhimrao Ambedkar University

Shubhini A Saraf ( $\square$ shubhini.saraf@gmail.com )

Babasaheb Bhimrao Ambedkar University https://orcid.org/0000-0002-4180-0931

\section{Research Article}

Keywords: Co-formers, J774A.1, Macrophages, carrageenan, cytokine

Posted Date: August 23rd, 2021

DOI: https://doi.org/10.21203/rs.3.rs-592061/v1

License: (1) (1) This work is licensed under a Creative Commons Attribution 4.0 International License. Read Full License 


\section{Abstract}

The present investigation deals with solubility enhancement of Etodolac (ETD) through co-crystals technique utilizing various co-formers and to evaluate their therapeutic efficacy against carrageenaninduced inflammation. Co-formers citric acid anhydrous and tartaric acid were selected to formulate ETD co-crystals to improve solubility and dissolution employing neat grinding technique. The prepared cocrystals were characterized for solubility enhancement, Fourier transform infrared spectroscopy (FTIR), differential scanning calorimetry (DSC), powder X-ray diffraction (PXRD), in vitro dissolution and stability studies. The co-crystals were further investigated for in vivo studies to assess their potential to cure paw edema in mice. The outcome of the study illustrated significantly improved solubility and dissolution of ETD up to 6.15 folds using citric acid. Approximately a two-fold reduction in nitric oxide and cytokines levels was observed with optimized formulation. Also, substantial inhibition of inflammation was observed in paw edema induced animals. In sight of the above results the co-crystal approach could be an alternative for enhanced therapeutic potential.

\section{Introduction}

Etodolac (ETD) is a non-steroidal anti-inflammatory agent of selective COX-2 inhibitor class used for treating osteoarthritis and rheumatoid arthritis, because of its therapeutic ability to inhibit prostaglandin synthesis [1]. ETD is a chiral drug with a stereogenic carbon atom consisting racemic mixture of [+]S and [-]R enantiomers and is commercially marketed in its racemic form [2]. The S-form of ETD is biologically active and $\mathrm{S}$-form possesses extensive binding to human serum albumin when compared with its $\mathrm{R}$ form [3] [4]. The poor aqueous solubility and extensive first pass metabolism are attributing factors to its low bioavailability. The second problem of ETD is related to its terminal half-life of $7 \mathrm{~h}$ which require frequent dosing leading to many dose associated side effects [5]. Repeated oral regimen of ETD causes various side effects viz. serious gastrointestinal disturbance such as ulcer, stomach or intestinal bleeding, chest pain and cardiovascular risk which could be fatal in some cases [6].

Various literature have revealed different customized solubility enhancement techniques such as salt formation, solid dispersion, use of surfactants, drug micronization, polymorphism, co-crystallisation, cosolvent, complexation etc. Co-crystal development has encouraged scientists to develop solid form of existing poorly water soluble parent drugs (active pharmaceutical ingredients (API) with improved physicochemical properties. This technique has resulted in improved solubility profile, dissolution rate, stability and bioavailability, without causing any alteration or chemical modification to the API [7]. Basically drugs are classified into four main groups according to their solubility and permeability as BCS I, II, III and IV. BCS class I and III group drugs possess high solubility while a low solubility is offered by BCS classes II and IV [8]. About $40 \%$ of drugs available in the market and $70-90 \%$ of drug candidates discovered fall under BCS II and IV category [9]. This high percentage of drugs having low solubility has underlined the importance of developing solubility enhancing techniques of drugs and their dosage form development [10]. 
In recent years, considerable work has been done in scheming and synthesis of multi-component crystals in the context of pharmaceutical co-crystals and this has emerged as an area of current interest. Cocrystal has extended consideration in recent years by researchers' due to its flexibility in designing and modifying physiochemical properties such as solubility, dissolution, stability and bioavailability, which play a major role in the development of an active pharmaceutical ingredient (API) into a successful drug candidate suitable for patient compliance [11]. There are a variety of techniques which are implicated in co-crystals preparation viz. solvent evaporation, solid state neat grinding, liquid assisted grinding, antisolvent addition, sono-crystallization, hot melt extrusion and supercritical fluid technology etc. [12] [11]. In the present study ETD co-crystals were designed by three different methods namely neat grinding, liquid assisted grinding, and solvent evaporation as desirable for optimization of the methodology. A wide range of pharmaceutical co-crystals have been reported till date utilizing co-formers which are considered as GRAS (generally recognized as safe) compounds comprising of food additives, preservatives and pharmaceutical excipients [13]. Chemical modification is bypassed in formation of pharmaceutical cocrystals as stated earlier and is also considerably safe for administration in view of the fact that excipients used are GRAS listed [14]. Co-crystals approach can also be utilized in altering the solubility of non-ionizable drugs for which salts approach cannot be utilized.

In the present study, an attempt has been made to formulate ETD co-crystals using citric acid anhydrous (CA) and tartaric acid (TA) which hold GRAS status with the aim to improve its physicochemical properties specifically solubility and dissolution rate. CA and TA possess high aqueous solubility [15]. These co-formers contain hydrogen bond donor and acceptor groups, which can be utilized in co-crystals formation of ETD leading to improved solubility. The present research was to investigate the practicability of co-crystals for peroral delivery and to overcome low solubility status of the drug. The basic initiative of the present work was taken on the basis of research work published in various literatures principally focusing the solubility enhancement of ETD using different techniques.

\section{Materials And Methods}

\subsection{Materials}

ET was purchased from M/s BMR Pharma \& Chemicals Ltd, Hyderabad. Methanol, potassium dihydrogen phosphate, sodium hydroxide, carrageenan, citric acid anhydrous, tartaric acid and l-ascorbic acid were purchased from M/s Loba Chemicals Pvt. Ltd, Mumbai. All chemicals, were of analytical grade and used without further purification. In-house distilled water was used throughout the experiment.

\subsection{Preparation of co-crystals}

Pharmaceutical co-crystals of ETD were prepared with different co-crystal formers using three different techniques viz. solvent drop grinding, neat grinding and solvent evaporation. Total nine formulations (SN1-SN9) were prepared in different molar ratio and w/w molar ratio of 1:1. Co-formers used for cocrystals formation of ETD were citric acid anhydrous (CA) and tartaric acid (TA). 


\subsection{Methods}

2.3.1 Neat/Dry grinding: API and co-former were taken in various molar ratios and varying weight ratio and were grounded together manually in a mortar and pestle at room temperature for 30 minutes as summarized in Table 1 [15].

2.3.2 Liquid assisted grinding: API and co-former in various molar ratio and varying weight ratios were grounded together manually in a mortar and pestle at $45^{\circ} \mathrm{C}$ temperature for $30 \mathrm{~min}$ along with drop wise addition of few $\mathrm{ml}$ (q.s.) of methanol, until a homogeneous paste was obtained. The paste was finally dried under vacuum, and co-crystals were collected [16].

2.3.3 Solvent evaporation technique: API and co-formers in various molar ratio and varying weight ratio were co-grounded together manually in a pestle and mortar at room temperature for 30 minutes and were transferred into a beaker containing $10 \mathrm{ml}$ methanol, kept under ambient condition for 2 days for the cocrystal formation followed by solvent evaporation. The co-crystals obtained were dried under vacuum and were procured till further use as described elsewhere [17].

Table 1

Physical appearance of co-crystals with CA and TA

Physical appearance of co-crystals with CA

\begin{tabular}{|lll|}
\hline S. No & Formulation ID & Physical appearance \\
\hline 1 & SN-1 & White crystalline \\
\hline 2 & SN-2 & Light yellow crystalline \\
\hline 3 & SN-3 & White crystalline \\
\hline 4 & SN-4 & White crystalline \\
\hline 5 & SN-5 & Creamish crystalline \\
\hline 6 & SN-6 & White crystalline \\
\hline 7 & SN-7 & Light brown crystalline \\
\hline 8 & SN-8 & Slightly yellow crystalline \\
\hline 9 & SN-9 & Light brown crystalline \\
\hline
\end{tabular}

\subsection{Characterization of co-crystals}

\subsubsection{Physical appearance}

The physical appearance of co-crystals was evaluated by visually.

\subsubsection{Melting point}


Primary confirmation of co-crystal formation was done through comparison of melting point of pure API, co-formers and co-crystals using capillary method. The melting point of a solid is the temperature at which the solid and the liquid exists equal vapor pressure. For determining melting point a small amount of sample was tapped into capillary and the capillary was placed in cavity of melting point apparatus (Bio Technics, BTI-34, Mumbai). The, melting range was recorded from the point at which sample begins to melt till it completely melts. All the experiments were done in triplicate.

\subsubsection{Scanning electron microscopy (SEM)}

The surface morphology and size of co-crystals was determined through SEM. Various images of API and co-crystals were acquired by scanning electron microscope (JEOL-JSM-6490LV, Japan). The samples were stored overnight in vacuum and were gold coated prior to observation. The coated samples were mounted on a stub and photographs were taken at various magnification.

\subsubsection{Differential Scanning Calorimetry (DSC)}

DSC thermo grams of ETD and its co-crystals were obtained using DSC, Model: 6200, Hitachi, Japan. DSC is a thermo analytical technique to identify the solid-state interactions between drug and co-former. The interaction or formation of new molecule can be studied through the shifts in peaks, and appearance of new peaks. About $5 \mathrm{mg}$ sample was loaded in aluminum pan along with a blank as reference.

Measurements were performed at a temperature range from $30^{\circ} \mathrm{C}-300^{\circ} \mathrm{C}$ with an increment of $10^{\circ} \mathrm{C} / \mathrm{min}$. Experiments were performed in triplicate.

\subsubsection{Fourier Transform Infrared (FT-IR) Studies}

FT-IR spectra of pure ETD, co-formers and selected co-crystals were recorded individually through FTIR spectrophotometer (Alpha Platium ATR, Germany). The pellets having zero porosity were prepared using potassium bromide $(\mathrm{KBr})$. For this, a few milligrams of sample was grounded with $\mathrm{KBr}$ in 1:100 ratio.

Further, the mixture was pressed using a hydraulic press to form pellets at a pressure of about $9 \mathrm{t} / \mathrm{in}^{2}$. Scans were recorded in the range of $400-4000 \mathrm{~cm}^{-1}$ at spectral resolution of $4 \mathrm{~cm}^{-1}$.

\subsection{Drug content analysis}

$10 \mathrm{mg}$ of each formulation was weighed and transferred to $10 \mathrm{ml}$ volumetric flask and dissolved in methanol. Absorbance was measured spectrophotometrically at $273 \mathrm{~nm}$ for estimation of drug content. Experiments were performed in triplicate.

\section{Drug content $=\frac{\text { Actual drug content }}{\text { theoretical drug content }} \times 100$}

\subsection{Drug solubility study}

The solubility of drug was evaluated in different solvents viz methanol, ethanol, dicholoromethane and water. The solubility study of ETD and its co-crystals was performed by shake flask method [16]. The solubility was analyzed in four different solvents viz. water, methanol, ethanol and dicholoromethane. 
ETD (10 mg) was added in $20 \mathrm{ml}$ of various solvents in a flask which was shaken over a water bath shaker at $25^{\circ} \mathrm{C} \pm 0.5^{\circ} \mathrm{C}$ at $100 \mathrm{rpm}$ over a period of $12 \mathrm{~h}$. Similarly co-crystals equivalent to $10 \mathrm{mg}$ of ETD were analyzed for solubility. The samples were withdrawn and filtered through membrane filter $0.45 \mu \mathrm{m}$, whattman membrane filter, diluted suitably and concentration of ETD was analysed through UV spectrophotometer at $\lambda_{\max } 273 \mathrm{~nm}$. The drug concentration in the filtrate was estimated and solubility was calculated using the calibration curve. All the experiments were performed in triplicate.

\subsection{Drug dissolution profile}

The co-crystals of ETD were prepared using CA and TA were subjected to dissolution study using USP type II (Paddle type) dissolution apparatus at $75 \mathrm{rpm}$ (Veego, India) in $500 \mathrm{ml}$ of phosphate buffer having variable $\mathrm{pH}$ of $4,6.8$ and 7.4 containing $1 \% \mathrm{w} / \mathrm{v}$ sodium lauryl sulphate (SLS) at $37 \pm 0.5^{\circ} \mathrm{C}$ in order to check its stability and release profile throughout the gastrointestinal tract. The samples were withdrawn at definite time intervals over a period of $12 \mathrm{~h}$ and were quantified using UV spectrophotometer (Labtronics-LT 2910) at $273 \mathrm{~nm}$. Simultaneously SN-5 (formulated as capsule) was also compared with marketed formulation (Etova-ER tablet $400 \mathrm{mg}$ ) at pH 6.8 .

\subsection{In vitro Cell Studies on Human Macrophage Cells [17; 18]}

\subsubsection{Cytotoxicity studies of etodolac cocrystals on Human Macrophage Cells}

In vitro cytotoxicity of etodolac and its cocrystals (SN5) were carried out on Human Macrophage Cells J774A.1 (4×105 per well) by MTT (3-(4, 5-dimethylthiazol-2-yl)-2, 5-diphenyl tetrazolium bromide) assay. All cells seeded in 96 well plates were treated with toxic control. Group III received formulation containing ETD and SN5, followed by incubation for $24 \mathrm{~h}$ with in concentrations 10,20 and $40 \mu \mathrm{M} / \mathrm{ml}$. The optical density values were determined at $540 \mathrm{~nm}$ using ELISA plate reader showing the cell cytotoxicity by staining live cell by $0.5 \mathrm{mg} / \mathrm{ml}$ MTT for $3 \mathrm{~h}$ (formazan crystal formation). Triplicates of each sample were analyzed.

\subsubsection{Assay for detection of nitric oxide (NO) and cytokine (IL-6 and TNF-a) release}

The effect of SN5 on induction of NO and cytokines was studied on Human Macrophage Cells J774A.1 $\left(4 \times 10^{5}\right.$ per well). The cells were seeded in 24 -well plate overnight. The confluent cells were treated with the three concentrations of toxic control. Group III received carrageenan ( $1 \% \mathrm{v} / \mathrm{v}$ carrageenan + formulation containing ETD and SN5 in LPS (Lipopolysaccharides) treated cells $(0.5 \mathrm{mg} / \mathrm{ml}$ of medium) and incubated for $24 \mathrm{~h}$. On completion of incubation, cells were collected and NO, TNF-a and IL-6 were estimated in cell supernatant using Griess reagent and murine-specific sandwich ELISA (R\&D system, USA) respectively, in accordance with the standard manufacturer's protocol.

\subsection{In vivo studies}


The in vivo study was performed according to the Declaration of Helsinki as amended in Seoul 2008 for humans and the European Community guidelines as accepted principles for the use of experimental animals and approved by the Institutional Animal Ethics Committee as per approval number 1451/PO/E/11/CPCSEA. For the study, animals were acclimatized under maintained laboratory conditions at ambient temperature of $25 \pm 2^{\circ} \mathrm{C}$ and relative humidity of $50 \pm 5 \%$ with a $12 \mathrm{~h} \mathrm{light} / 12 \mathrm{~h}$ dark cycle. Swiss albino mice weighing 100-150 gms were fed with a commercial pellet diet and water ad libitum. Experimental animals were divided into 4 groups, containing 6 animals each. Group I was taken as negative control. Group II received carrageenan ( $1 \% \mathrm{v} / \mathrm{v}$ carrageenan) and taken as toxic control. Group III received carrageenan ( $1 \% \mathrm{v} / \mathrm{v}$ carrageenan + formulation containing ETD) and Group IV received carrageenan ( $1 \% \mathrm{v} / \mathrm{v}$ carrageenan + marketed formulation) through oral route in an equivalent dose of 10 $\mathrm{mg} / \mathrm{kg}$ to toxic control.

\subsubsection{Paw edema anti-inflammatory test}

Paw edema was induced in swiss albino mice (150-200 g) by injecting $100 \mu \mathrm{l}$ of $1 \%$ carrageenan diluted in saline in the left hind foot pad. Paw volumes were determined in all the groups using digital vernier caliper at various time points i.e. $0,1,2,4,6,8,10,12$ and $24 \mathrm{hr}$. The increase in paw volume was calculated by subtracting the initial paw volume (basal) to the paw volume measured at each time point and the percentage of inhibition was calculated [19].

$\%$ inhibition $=\frac{\text { control }- \text { Test }}{\text { Control }} \times 100$

\subsubsection{Pharmacokinetic Studies}

Pharmacokinetic studies were performed using HPLC (Shimadzu LC20AD) having C-18 reverse phase column. Blood samples from each group were withdrawn from saphenous vein at 0, 5, 15, 30 min and 1 , $2,4,8,16,24,48 \mathrm{~h}$. The withdrawn blood was centrifuged at $10,000 \mathrm{rpm}$, at $4^{\circ} \mathrm{C}$ for $15 \mathrm{~min} .100 \mu \mathrm{l}$ of serum was diluted with $100 \mu \mathrm{l}$ acetonitrile and vortexed for $30 \mathrm{~min}$ followed by centrifugation for $15 \mathrm{~min}$ at $10,000 \mathrm{rpm}$ and $4^{\circ} \mathrm{C}$. The prepared sample was pipetted, deprotonated and reconstituted with acetonitrile. The wavelength was set at $273 \mathrm{~nm}$, the retention time of ETD was found to be $3.453 \mathrm{~min}$. Acetonitrile: water in a ratio of 95:5 was used as mobile phase.

\subsection{Stability Studies}

Stability studies were performed as per ICH guidelines, as applicable. All prepared batches were visually observed for turbidity and analyzed for drug content. The formulations were kept in transparent containers for stability assessment over a period of 90 days at $4^{\circ} \mathrm{C} \pm 2^{\circ} \mathrm{C}, 25^{\circ} \mathrm{C} \pm 2^{\circ} \mathrm{C}$ and $40^{\circ} \mathrm{C} \pm 2^{\circ} \mathrm{C}$ as per ICH guidelines. Samples were assessed at $0,15,30,45$, and 90 days. Simultaneously accelerated stability testing of optimized batch was performed to estimate the shelf life of the formulation. For this the formulations were subjected to variable temperatures viz. $25^{\circ} \mathrm{C} \pm 2{ }^{\circ} \mathrm{C}, 45^{\circ} \mathrm{C} \pm 2^{\circ} \mathrm{C}$ and $75 \% \pm 5 \% \mathrm{RH}$. 
Variation in the residual drug content after time interval of 30,60 and 90 days were analyzed. All experiments were performed in triplicate.

\section{Results}

\subsection{Physical appearance}

The physical appearance of co-crystals with different co-formers was determined visually. It is represented in Table 1.

\subsubsection{Melting point determination}

Melting point of formulations was determined using capillary tube method. The melting point of cocrystals ranges from $135^{\circ} \mathrm{C}$ to $156^{\circ} \mathrm{C}$. On comparing with pure ETD $\left(146.5^{\circ} \mathrm{C}\right)$, it was observed that the melting point co-crystal, had significant deviation with respect to the melting point of pure drug and individual co-formers, indicating interaction between them. This parameter was used as a preliminary test for the confirmation of co-crystal formation. The melting point of formulations with various co-formers is represented in the given Table 1.

\subsubsection{Scanning electron microscopy (SEM)}

The SEM images of co-crystals revealed fused masses in SN-3 (Fig. 1, b). Such co-crystals have a lesser solubility because of their complex morphology. While SN-5 and SN-9 (Fig. 1c \& d) showed irregular and asymmetrical structure, indicating greater solubility. The surface area is greater in such structures than those of fused masses as in SN-3, resulting in better solubility. The irregular shape of co-crystals is able to display maximum solubility as has been reported in earlier studies. SEM images of pure drug ETD is shown in Fig. 1 (a), reporting compact masses, indicating lower solubility. SEM images of pure drug ETD is shown in Fig. 1(a).

\subsubsection{Differential scanning calorimetry (DSC)}

DSC analysis has been considered to be an important and very useful thermo-analytical technique in the characterization of the solid-state interactions between drug and co-former through the shifts in peaks and appearance of new peaks. The sharp melting peak of ETD was observed at $143.7^{\circ} \mathrm{C}$ while that of cocrystal prepared from CA, SN-3 and SN-9 were observed at $150.39^{\circ} \mathrm{C}$ and $150.39^{\circ} \mathrm{C}$ respectively. The melting of co-crystal prepared with TA was observed at $156.69^{\circ} \mathrm{C}$. From the DSC thermograms, it was identified that the thermograms of the co-crystals possess different pattern and intensity as compared to ETD and co-former (TA) confirming interaction between them. This shift in the melting point of co-crystal was due to change in crystal lattice of ETD in the presence of co-former. The DSC thermogram of drug, co-former, and co-crystal are represented in the Fig. 2a(i-iv).

The increase in melting point could be due to presence of different co-formers used with pure drug, which indicates the possibility of enhanced solubility of co-crystals. This could be due to formation of ETD-TA 
and ETD-CA which hold higher number of hydrogen bonds when compared to pure ETD. This, results in an increase in the polarity of the co-crystals which also corroborate enhance solubility and melting point as observed in case of SN-5 co-crystals (confirmed by our results $79.99 \mathrm{mg} / \mathrm{L} / 156.59^{\circ} \mathrm{C}$ ).

\subsubsection{Fourier transform infrared spectroscopy (FTIR)}

FTIR is an excellent technique to establish interaction taking place between drug and co-former. The FTIR spectrum results revealed a difference in spectrum of ETD from that of co-crystal. The appearance of new peaks, indicates interaction between ETD and co-former. By comparing FTIR spectra of ETD (Supplementary Fig. 1, a) and formulation(s) SN-3 (Supplementary Fig. 1, b), SN-5 (Supplementary Fig. 1, c), SN-9 (ETD-TA) Supplementary Fig. 1 (d) it was confirmed that the interaction between ETD and CA/TA occurred during the formation of co-crystals. The formation of new peaks at 3495.2, 3589.7, 2973.5, 2622.7, $2006.2 \mathrm{~cm}^{-1}$ confirmed the interaction between ETD and co-former, however there was no alteration in major peaks, indicating absence of drug degradation. Peaks observed in the region of $900-$ $1500 \mathrm{~cm}^{-1}$, indicate the occurrence of hydrogen bonding.

\subsubsection{Powder X-ray diffraction (PXRD)}

Powder X-ray diffraction pattern of drug and co-crystals were utilized to confirm the result of thermal method for co-crystal characterization. The detection of the new phases of crystal lattice could be justified by PXRD pattern. The different PXRD pattern for co-crystals from those of individual component (drug) confirmed the formation of new phases and also justified the formation of co-crystals. The assessment of PXRD pattern of ETD and its co-crystals reveals that there could be formation co-crystal as supplementary intense peaks were observed in co-crystals. It confirms development of new crystalline phases in co-crystals. The crystallogram pattern of pure ETD and its co-crystals are shown in (Fig. 2b i and ii). Characteristic peaks in crystallogram of pure drug appeared at different position at ${ }^{\circ} 2$ theta scale$10.25^{\circ}, 16.28^{\circ}, 16.58^{\circ}, 23.29^{\circ}, 24.50^{\circ}$ having intensities in percentage $100.00,24.60,32.42,45.36,24.58$ respectively. Characteristic peaks of co-crystal with CA appeared at different position at ${ }^{\circ} 2$ theta scale $10.39^{\circ}, 16.39^{\circ}, 18.21^{\circ}, 19.59^{\circ}, 26.17^{\circ}, 31.10^{\circ}$ having intensities in percentage $86.30,51.82,16.02,15.15$, $100.00,11.87$ respectively. The peak at $10.39^{\circ}$ is almost same as in the crystallogram of drug but some new peaks were observed at $18.21^{\circ}, 19.59^{\circ}, 26.17^{\circ}, 31.10^{\circ}$. These new peaks confirmed the formation of new crystal lattice pattern in the co-crystal as compared to pure ETD.

\subsection{Drug and co-crystal solubility study}

ETD has poor water solubility of $13.4 \mathrm{mg} / \mathrm{L}$, however it possesses good solubility in organic solvents viz methanol, ethanol and dicholoromethanol. The solubility of pure drug in distilled water was found to be $19.35 \mathrm{mg} / \mathrm{L}$. Solubility of co-crystal in distilled water was found maximum of $79.99 \mathrm{mg} / \mathrm{L}$ in case of SN-5 followed by SN-9 $77.98 \mathrm{mg} / \mathrm{L}$ recorded in Table 2. The solubility of pure drug in phosphate buffer of $\mathrm{pH} 6.8$ was found to be $18.06 \mathrm{mg} / \mathrm{L}$. Solubility of co-crystals in phosphate buffer, $\mathrm{pH} 6.8$ was found maximum $48.19 \mathrm{mg} / \mathrm{L}$ in case of SN-5 followed by SN-3 $42.44 \mathrm{mg} / \mathrm{L}$ and is recorded in Table 2. From the above data it can be concluded that the co-crystals prepared with CA showed highest solubility in distilled water as well as in phosphate buffer ( $\mathrm{pH}$ 6.8). Solubility of pure drug and its co-crystals in distilled water and 
phosphate buffer ( $\mathrm{pH}$ 6.8) is represented in the fold increase in Fig. 3, a and $\mathrm{b}$. When represented as percentage, the $\%$ increase in solubility was $13.9,61.4,58.1 \%$ in distilled water and $12.9,33.8,29.1 \%$ in phosphate buffer ( $\mathrm{pH}$ 6.8). The maximum solubility fold increase in the distilled water was found to be $61.4 \%$ as shown in Table 3.

Table 2

Co-crystals of ETD-CA (SN-1 to SN-5) and ETD-TA (SN-6 to SN-9)

\begin{tabular}{|c|c|c|c|c|}
\hline S. No & Formulation & Method of preparation & Ratio (molar or w/w) & Melting range $\left({ }^{\circ} \mathrm{C}\right)$ \\
\hline 1 & $\mathrm{SN}-1$ & Neat/dry grinding & $1: 2$ molar ratio & $135-138^{\circ} \mathrm{C}$ \\
\hline 2 & $\mathrm{SN}-2$ & Neat/dry grinding & $1: 5$ molar ratio & $143-146^{\circ} \mathrm{C}$ \\
\hline 3 & SN-3 & Solvent assisted/ wet grinding & $1: 5$ molar ratio & $148-150^{\circ} \mathrm{C}$ \\
\hline 4 & $\mathrm{SN}-4$ & Solvent evaporation technique & $1: 2$ molar ratio & $147-149^{\circ} \mathrm{C}$ \\
\hline 5 & SN-5 & Solvent evaporation technique & $1: 5$ molar ratio & $149-153^{\circ} \mathrm{C}$ \\
\hline 6 & SN-6 & Neat/dry grinding & $1: 2$ molar ratio & $146-148^{\circ} \mathrm{C}$ \\
\hline 7 & SN-7 & Neat/dry grinding & $1: 5$ molar ratio & $151-154^{\circ} \mathrm{C}$ \\
\hline 8 & SN-8 & Solvent assisted/ wet grinding & $1: 5$ molar ratio & $154-154^{\circ} \mathrm{C}$ \\
\hline 9 & SN-9 & Solvent evaporation technique & $1: 5$ molar ratio & $153-156^{\circ} \mathrm{C}$ \\
\hline
\end{tabular}

Table 3

Solubility of co-crystal in distilled water (DW) and buffers $\mathrm{pH} 6.8$

\begin{tabular}{|c|c|c|c|c|}
\hline \multirow[t]{2}{*}{ S. No } & \multirow[t]{2}{*}{ Co-former used } & \multirow[t]{2}{*}{ Formulation ID } & \multirow[t]{2}{*}{ Solubility in DW (mg/L) } & \multirow{2}{*}{$\begin{array}{l}\text { Solubility }(\mathrm{mg} / \mathrm{L}) \\
\text { PBS } 6.8\end{array}$} \\
\hline & & & & \\
\hline 1 & \multirow[t]{5}{*}{ CA anhydrous } & SN-1 & 61.50 & 29.15 \\
\hline 2 & & SN-2 & 68.89 & 30.58 \\
\hline 3 & & SN-3 & 75.37 & 42.44 \\
\hline 4 & & SN-4 & 57.68 & 31.10 \\
\hline 5 & & SN-5 & 79.99 & 48.19 \\
\hline 6 & \multirow[t]{4}{*}{ TA } & SN-6 & 53.45 & 22.93 \\
\hline 7 & & SN-7 & 64.77 & 20.21 \\
\hline 8 & & SN-8 & 68.05 & 28.90 \\
\hline 9 & & SN-9 & 77.98 & 39.05 \\
\hline
\end{tabular}


The in-vitro drug release data reveals that co-crystals with ETD-CA and ETD-TA, showed best release profile, as represented in Supplementary Fig. 2a-c respectively. The co-crystals formed with CA, showed a release ranging from $80.54 \% \pm 1.985 \%$ to $92.098 \pm 1.032 \%$ at $\mathrm{pH} 6.8$ which is enhanced as compared to $61.089 \pm 0.78 \%$ of pure ETD. For two formulations i.e. SN-3 and SN-5, maximum release was observed for an extended period of time i.e. $12 \mathrm{~h}$. Out of these, SN-5 displayed $80.54 \% \pm 1.985 \%$ in $6 \mathrm{~h}$ and $94.80 \pm$ $0.45 \%$ in $12 \mathrm{~h}$ at $\mathrm{pH}(6.8)$. This suited us the best and was selected as the optimized batch as it showed prolonged release. The formulation with TA, SN-9 showed drug release for an extended period of time i.e. $94.119 \pm 1.021 \%$ in $12 \mathrm{~h}$ at $\mathrm{pH}(6.8)$, and in case of $\mathrm{pH} 7.4$ and 4 formulation SN-5 showed highest release of $83.551 \pm 2.43 \%$ and $84.976 \pm 0.65 \%$ respectively, among all the 9 formulations. Hence, the release pattern was dependent on the type of co-former used. From this release profile it could be interpreted that the co-crystals formed with CA displayed highest solubility as well as best release profile. Formulation showed $76.007 \pm 1.72 \%$ to $83.551 \pm 2.43 \%$ release in $\mathrm{pH} 7.4$ as compared to $54.089 \pm 1.34 \%$ that possessed by pure ETD. While in case $\mathrm{pH} 4$ the release ranges from $72.909 \pm 1.77 \%$ to $84.976 \pm$ $0.65 \%$ which was much higher when compared with pure ETD that gives $58.089 \pm 0.99 \%$ release. When compared to marketed formulation $\mathrm{SN}-5$ displayed a better release over a period of 24 hours. The marketed formulation showed $67.98 \pm 1.32 \%$ while $S N-5$ showed $90.63 \pm 2.43 \%$ release over a period of 24 hours which is significantly higher. Percentage cumulative drug release of capsule (SN-5) vs marketed formulation is shown in Fig. 4.

\subsection{In vitro cytotoxicity of etodolac co-crystals on Human Macrophage Cells}

For cytotoxicity study on the Human Macrophage Cells, the cells were treated with three concentrations $(10,20$ and $40 \mu \mathrm{M} / \mathrm{ml})$ of ETD and SN5. The data showed that cytotoxic effect was not significant even at higher concentrations of treatment and SN5 demonstrated fair cyto-compatible effect on macrophages (Fig. 5a).

\subsubsection{Assay for detection of nitric oxide (NO) and cytokine (IL-6 and TNF-a) release}

Pretreatment of $\mathrm{J} 774$ macrophages with LPS $(0.5 \mathrm{mg} / \mathrm{l})$ resulted in augmenting in NO and cytokine levels, when the treatment was compared with the ETD and SN5 treated cells. Results displayed a significant $(p<0.05)$ decrease in NO concentration by ETD and SN5 (Fig. 5b). SN5 significantly $(p<0.05)$ decreases the NO nearly 2 folds when compared with ETD. SN5 also demonstrated a significant reduction in levels of IL- 6 in comparison to control and ETD. It displayed a concentration dependent inhibition of IL6 (Fig. 5b). Whereas, a similar effect was observed on TNFa levels with ETD and SN5. Both displayed a marked reduction as compared to control (Fig. 5c).

\subsection{Stability test and shelf life}

The purpose of stability testing is to provide evidence on how the quality of a formulation varies with time under the influence of a variety of environmental factors such as temperature. The present study is 
desired to test the stability of co-crystal based formulation of ETD drug. The stability study on prepared formulation was performed by storing the formulations at low temperature such as $4 \pm 2{ }^{\circ} \mathrm{C}, 30 \pm 2{ }^{\circ} \mathrm{C}$ and at $40 \pm 2{ }^{\circ} \mathrm{C}$ at $75 \pm 5 \% \mathrm{RH}$ for 90 days represented in Table 4 . The stability was calculated in terms of drug content. It was observed that at $4 \pm 2^{\circ} \mathrm{C}$ and $25 \pm 2^{\circ} \mathrm{C}$ there was insignificant decrease in the drug content percentage, while at higher temperature of $40 \pm 2^{\circ} \mathrm{C}$ there was degradation in drug content. The shelf life calculated from stability data is recorded in Table 5 . The formulation code SN-5 was used for stability study. The formulations were stored at $4 \pm 2^{\circ} \mathrm{C}, 30 \pm 2^{\circ} \mathrm{C}$ and $40 \pm 2^{\circ} \mathrm{C}, 75 \pm 5 \% \mathrm{RH}$. Variation in the residual drug content after time interval of 30,60 and 90 days were analyzed. There were no significant changes in the physical appearance at $4 \pm 2{ }^{\circ} \mathrm{C}$, room temperature and hot air oven.

Table 4

Stability data for co-crystal of ETD SN-5

\begin{tabular}{|llll|}
\hline S. No. & Temperature & Time interval (months) & Drug Content (\%) \\
\hline $\mathbf{1}$ & Initial & 0 & 100 \\
\hline $\mathbf{2}$ & $4 \pm 2^{\circ} \mathrm{C}$ (Refrigerator) & 1 & $93.92 \pm 0.04$ \\
& & 2 & $93.55 \pm 0.5$ \\
& & 3 & $94.01 \pm 0.2$ \\
\hline 3 & $25 \pm 2^{\circ} \mathrm{C}$ (Room temperature) & 1 & $91.39 \pm 0.1$ \\
& & 2 & $87.02 \pm 0.3$ \\
& & 3 & $87.24 \pm 0.05$ \\
\hline & $45 \pm 2^{\circ} \mathrm{C}$ (Hot air oven) & 1 & $87.33 \pm 0.03$ \\
& & 2 & $86.02 \pm 0.2$ \\
& & 3 & $84.01 \pm 0.1$ \\
\hline
\end{tabular}

Table 5

Shelf -life of optimized formulation

\begin{tabular}{|c|c|c|c|c|}
\hline \multirow[t]{2}{*}{ S.No. } & \multirow[t]{2}{*}{ Parameter } & \multicolumn{3}{|c|}{ Storage condition } \\
\hline & & $4 \pm 2^{\circ} \mathrm{C}$ & $25 \pm 2^{\circ} \mathrm{C}$ & $45 \pm 2^{\circ} \mathrm{C}$ \\
\hline 1. & $\mathrm{~K}\left(\right.$ day $\left.^{-1}\right)$ & $1.24 \times 10^{-4}$ & $4.34 \times 10^{-5}$ & $4.47 \times 10^{-5}$ \\
\hline 2. & $\mathrm{~T}_{1 / 2}$ (days) & 4914.08 & 1171.81 & 1010.51 \\
\hline 3. & $\mathrm{~T}_{10}$ (days) & 723.5 & 179.73 & 1826.69 \\
\hline
\end{tabular}

The residual drug content values ETD co-crystals stored at $4 \pm 2^{\circ} \mathrm{C}$ was found to be higher as compared with formulation stored at room temperature and $45 \pm 2^{\circ} \mathrm{C}$. So it can be concluded that the optimized formulation was more stable at $4 \pm 2^{\circ} \mathrm{C}$ and tends to degrade faster at higher temperature. Thus, it is recommended that the formulation should be stored in a refrigerator for a longer shelf life. The co- 
crystals degraded more at higher temperature of $40 \pm 2^{\circ} \mathrm{C}$ due to trace amount of free drug in the cocrystals; this can be confirmed due the FTIR peaks and DSC thermogram pattern. Some changes in FTIR peaks were seen which evident the chemical interaction between the drug and co-former. DSC thermogram shows an increase in melting point to $168.56^{\circ} \mathrm{C}$ in SN-5. The formulation SN-5 was taken on the basis of results obtained from above studies stability study. The formulations were stored at $4 \pm 2{ }^{\circ} \mathrm{C}$, $30 \pm 2^{\circ} \mathrm{C}$ and $40 \pm 2^{\circ} \mathrm{C}, 75 \pm 5 \% \mathrm{RH}$. Variation in the residual drug content after time interval of 30,60 and 90 days were analyzed. There were no significant changes in the physical appearance at $4 \pm 2 \bowtie \mathrm{C}$, room temperature and hot air oven. Effect of aging on drug content and log \% drug content is shown in Supplementary Fig. 3. FTIR and DSC thermogram of formulation SN-5 after stability studies i.e. 90 days is shown in Supplementary Fig. 4.

\subsection{Pharmacodynamic parameter: Paw edema anti- inflammatory test}

Paw edema anti-inflammatory test revealed significant difference in percentage inhibition of edema in case of SN-5 and marketed formulation. The marked formulation showed a reduction in edema from 1.09 to 0.9 while $\mathrm{SN}-5$ showed a reduction from 1.12 to 0.88 . SN-5 and marketed formulation were significantly different from each other indicating SN-5 was significantly $(P<0.05)$ superior as compared to marketed formulation. Observations of paw-edema anti-inflammatory test are enlisted in Table 6. Images for this test are provided in Fig. 6 (a) and (b). Table 6 depicts the comparative anti-inflammatory response and percentage inhibition in the inflammation subsequent to carrageenan administration in various groups administered with different formulation. The data reveals higher anti-inflammatory potential of test formulation (co-crystals) when compared with marketed formulation.

\section{Table 6. Percentage inhibition in Paw Edema Anti-inflammatory test}




\begin{tabular}{|c|c|c|c|c|c|c|}
\hline \multirow{4}{*}{ S.No. } & \multirow{3}{*}{$\begin{array}{l}\text { Time } \\
\text { (hrs) }\end{array}$} & \multicolumn{3}{|c|}{ (Paw thickness of rats) (cms) } & \multicolumn{2}{|l|}{$\%$ inhibition } \\
\hline & & \multirow[t]{2}{*}{ Control } & Test/ & Marketed & \multirow[t]{3}{*}{ Test/ Formulation } & \multirow[t]{3}{*}{ Marketed } \\
\hline & & & \multicolumn{2}{|l|}{ Formulation } & & \\
\hline & Initial & $0.48 \pm 0.04^{\star \star \star}$ & $0.65 \pm 0.1$ & $0.59 \pm 0.5$ & & \\
\hline 1 & 1 & $1.16 \pm 0.1$ & $1.01 \pm 0.13$ & $1.05 \pm 0.32$ & 12.93 & 9.48 \\
\hline 2 & 2 & $1.29 \pm 0.2$ & $1.11 \pm 0.32$ & $1.14 \pm 0.13$ & 29.85 & 19.97 \\
\hline 3 & 4 & $1.34 \pm 0.09$ & $0.94 \pm 0.1$ & $1.01 \pm 0.43$ & 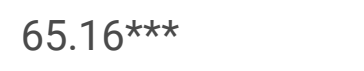 & 61.54 \\
\hline 4 & 6 & $1.51 \pm 0.25$ & $0.76 \pm 0.15$ & $0.91 \pm 0.28$ & 61.05 & 39.73 \\
\hline 5 & 8 & $1.49 \pm 0.42$ & $0.72 \pm 0.36$ & $0.99 \pm 0.15^{\star \star}$ & $51.67 * \star$ & $32.65^{\star \star}$ \\
\hline 6 & 10 & $1.43 \pm 0.32$ & $1.12 \pm 0.42$ & $1.09 \pm 0.32$ & 21.67 & 20.03 \\
\hline 7 & 12 & $0.69 \pm 0.23$ & $0.61 \pm 0.21^{\star \star \star}$ & $0.62 \pm 0.13$ & 11.58 & $10.14^{\star}$ \\
\hline 8 & 24 & $0.9 \pm 0.1$ & $0.88 \pm 0.32$ & $0.9 \pm 0.15$ & 2.22 & 0 \\
\hline
\end{tabular}

Values are (Mean $\pm S D$ ), each group contains 6 animals. Comparisons were made on the basis of the one-way ANOVA followed by Bonferroni test. All groups were compared to the initial values $\left({ }^{*} p<0.05\right.$, $\star \star \mathrm{p}<0.01, * \star * \mathrm{p}<0.001)$

\subsubsection{Pharmacokinetic parameter: in vivo study}

Calibration plot in acetonitrile: The stock solution $(1000 \mu \mathrm{g} / \mathrm{ml})$ of ETD was prepared in ACN. It was diluted to $100 \mu \mathrm{g} / \mathrm{ml}$. The UV spectrum was recorded in the range of $200-400 \mathrm{~nm}$ using HPLC (ShimadzuLC-20AD, Japan). Wavelength of maximum absorbance $\left(\lambda_{\max }\right)$ was found to be $273 \mathrm{~nm}$ which was nearest to reported $\lambda_{\max }$ i.e $270 \mathrm{~nm}$. It ensured that the drug was of working standard. In PK, $\mathrm{C}_{\max }$ of ETD and $\mathrm{SN}-5$ is $4.19 \mu \mathrm{g} / \mathrm{ml}$ and $9.12 \mu \mathrm{g} / \mathrm{ml}, \mathrm{t}_{\mathrm{max}}$ of ETD and SN-5 is $3.01 \mathrm{~h}$ and $4.01 \mathrm{~h}$. $\mathrm{C}_{\max }$ of SN-5 was found to be more as compared to that of ETD and $t_{\max }$ got decreased in case of SN-5 than ETD. So, it showed that the solubility and bioavailability got enhanced. The $t_{1 / 2}$ of formulation was also increased indicating its prolonged release. The pharmacokinetic parameters are recorded in Table 7. 
Table 7

Pharmacokinetic Parameters of ETD and optimized formulation

\begin{tabular}{|llll|}
\hline S.No. & Parameter & ETD & Formulation \\
\hline $\mathbf{1}$ & $\mathrm{C}_{\max }(\mu \mathrm{g} / \mathrm{ml})$ & 4.19 & 9.12 \\
\hline $\mathbf{2}$ & $\mathrm{T}_{\max }(\mathrm{h})$ & 3.01 & 4.00 \\
\hline $\mathbf{3}$ & AUCINF (observed) & 1068.55 & 2198.76 \\
\hline $\mathbf{4}$ & AUMCINF & 32735.96 & 43999.56 \\
\hline $\mathbf{5}$ & Lambda & 0.2001 & 0.1090 \\
$\mathbf{6}$ & t1/2 (h) & 9.04 & 20.11 \\
\hline $\mathbf{7}$ & Cl(observed) & 0.0009 & 0.0005 \\
\hline $\mathbf{8}$ & MRT(h) & 9.58 & 10.79 \\
\hline $\mathbf{9}$ & MRTNF & 30.63 & 36.06 \\
\hline
\end{tabular}

\section{Discussion}

Pharmaceutical co-crystallization is a novel technique to alter the physicochemical properties of API to fine-tune its bioavailability and solid-state properties. In this research work, different co-formers with different functional groups like carboxylic acid, hydroxyl, was tried in different molar or w/w ratio to form co-crystals of ETD. The CA and TA were used as co-crystal formers. Several methods were used in the cocrystal formation i.e. neat grinding method, solvent assisted grinding, and solvent evaporation technique. Different ratios of co-former i.e. CA and TA were used to form co-crystals. Co-crystals were prepared by dry grinding; solvent assisted grinding and solvent evaporation method. Using different ratio of drug-coformer, nine pre-optimized formulations of different compositions were prepared.

\subsection{Mechanism of bonding between etodolac, citric acid and tartaric acid}

ETD ( \pm , RS-1,8-Diethyl-4,9-dihydro-3H-pyrano[3,4-b]indol-1-yl) acetic acid) formed co-crystals with CA (2hydroxy-1,2,3-propanetricarboxylic acid) and TA (2,3-dihydroxybutanedioic acid) with the help of the intermolecular bonding, Vander Wall bonding and hydrogen bonding. ETD contained acetic acid group which formed hydrogen bond, due to the hydroxyl group which bonded to the hydrogen of CA and TA. The co-crystal formers also produced $\mathrm{N}-\mathrm{H} \cdots \mathrm{N}$ hydrogen bond as well as $\mathrm{N}-\mathrm{H} \cdots \mathrm{O}$ pair-wise hydrogen bonds, and also the weaker aromatic $\pi \cdots \pi$ interactions, which jointly took part in the crystal packing. The proposed mechanism of formation of co-crystals was further supported by the pKa values of the compounds. Since, the pKa values had no major difference, the possibility of proton transfer, i.e. salt 
formation, might not be significant. The non-covalent interactions provided a thermodynamically stable crystal lattice arrangement and imparted a crystalline nature to the co-crystals, with improved solubility and significantly lower melting temperatures in comparison to pure drug crystals as these were weaker bonds than the covalent bonds.

Based on different characterization findings the release of three optimized formulations (SN-3, SN-5 and SN-9) was checked at $\mathrm{pH}$ 4.0, 6.8 and 7.4 and it was compared with \% cumulative release of ETD. The percentage cumulative release of co-crystals in the acidic $\mathrm{pH}$ was found to be minimum due to the acidic nature of the drug. Maximum percentage cumulative release of co-crystals was found to be $83.551 \%$ at $12 \mathrm{~h}$. From all in-vitro drug release data of co-crystals with ETD-CA and ETD-TA, It was concluded that the co-crystal with CA (ETD-CA) showed best release profile. For some of the co-crystals formulated with CA, formulations $\mathrm{SN}-3$ and $\mathrm{SN}-5$ showed maximum release for an extended period of time i.e. $24 \mathrm{~h}$. Out of these two, SN-5 displayed $80.5465 \%$ release in $6 \mathrm{~h}$ and $94.808 \%$ in $24 \mathrm{~h}$ at pH (6.8). Therefore, it was selected as the optimized batch. Hence, the release pattern depended on the type of co-former used. From this release profile it could be revealed that the co-crystals formed with CA displayed highest solubility as well as best release profile.

The calculated regression coefficients for zero order, first order, Higuchi's models and Korsmeyer-peppas were $0.574,0.804,0.979$ and 0.964 for SN- 5 batch of co-crystals. It was found that in vitro \% drug release of $\mathrm{SN}-5$ batch of co-crystals was best explained by Higuchi's models as the plot showed the highest linearity [20; 21].

The solubility studies were performed with the ETD and co-crystals in distilled water and PBS pH 6.8. The solubility of ETD, ETD-CA and ETD-TA was found to be $19.35,79.99$ and $77.98 \mathrm{mg} / \mathrm{L}$ in distilled water. The solubility of ETD, ETD-CA and ETD-TA was found to be $18.06,48.19$ and $39.05 \mathrm{mg} / \mathrm{L}$ in PBS pH 6.8 . The increase in solubility of ETD, ETD-CA and ETD-TA was found to be $1.39,6.14$ and 5.81 -fold in distilled water. The increase in solubility of ETD, ETD-CA and ETD-TA was found to be 1.29, 3.38 and 2.91 folds in PBS pH 6.8. This denoted that the solubility increase was more in distilled water than PBS pH 6.8. The maximum increase in solubility (61.4\%) was seen in SN-5. Based on overlay graph findings dissolution study was performed at three different $\mathrm{pH}$. Batch SN-3, SN-5 and SN-9 showed faster \% cumulative release. The SN-5 and SN-9 co-crystals showed good solubility due to the irregular and asymmetrical structure of the co-crystals as seen in SEM images. The irregular shaped co-crystals showed maximum solubility.

These co-crystals were characterized by melting point and change in melting point was observed i.e. melting point was increased due to the different co-formers used and it further denoted increase in solubility of co-crystal due to the ability of a molecule to pack tightly into a crystal lattice. A slight shift in FTIR peaks were found which reflected some interaction between drug and co-formers but no change was seen in the chemical properties of drug. SEM images of co-crystals were observed, they were irregular in shape. This irregularity in shape is probable reason for enhanced solubility [11]. 
In DSC, the melting point was increased because different co-formers were used with pure drug and it denoted increase in solubility of co-crystals due to ETD-TA and ETD-CA formation, with more hydrogen bonds. Thus, the polarity of the co-crystals increased which confirmed the maximum solubility and maximum melting point of SN-5 $\left(79.99 \mathrm{mg} / \mathrm{L}\right.$ and $\left.156.59^{\circ} \mathrm{C}\right)$.

The PXRD crystallogram pattern of co-crystals showed a variation in peak intensity and formation of new peaks as compared to that of the pure ETD. Hence, it revealed that some chemical bonding occurred between pure ETD and co-formers resulting in the formation of co-crystals. This change in the PXRD pattern could be due to the change in the crystal lattice structure owing to the interaction between the drug and co-formers [11]. Characteristic peaks in crystallogram of pure drug appeared at different position at ${ }^{\circ} 2$ theta scale- $10.25^{\circ}, 16.28^{\circ}, 16.58^{\circ}, 23.29^{\circ}, 24.50^{\circ}$ with intensities in percentage 100.00 , $24.60,32.42,45.36,24.58$ respectively. Characteristic peaks in crystallogram of co-crystal with citric acid (ETD-CA, SN-5) as co-former, appeared at different position at ${ }^{\circ} 2$ theta scale- $10.39^{\circ}, 16.39^{\circ}, 18.21^{\circ}$, $19.59^{\circ}, 26.17^{\circ}, 31.10^{\circ}$ with intensities in percentage $86.30,51.82,16.02,15.15,100.00,11.87$ respectively. The peak at $10.39^{\circ}$ was almost same as in the crystallogram of drug but some new peaks were observed at $18.21^{\circ}, 19.59^{\circ}, 26.17^{\circ}, 31.10^{\circ}$. These new peaks confirmed the formation of new crystals lattice pattern in the co-crystal as compared to the pure drug. These studies indicated the formation of new crystalline phase due to physical or chemical interaction between drug and co-former. The main aim behind formation of co-crystals was to increase aqueous solubility of drug and as well as to improve its dissolution profile [22].

Drug content for optimized batch was found to be $85.23 \%$. Capsules of SN-5 were prepared and compared with marketed ETD, \% release of SN-5 capsules showed maximum release in $4 \mathrm{~h}$ whereas marketed ETD showed maximum release in $12 \mathrm{~h}$. It denoted that the solubility of co-crystals is more as compared to ETD.

The optimized batch SN-5 was used for in vivo study and stability studies. The formulation SN-5 was used for stability studies. Both the formulations were stored at $4 \pm 2^{\circ} \mathrm{C}, 30 \pm 2^{\circ} \mathrm{C}$ and $40 \pm 2{ }^{\circ} \mathrm{C}, 75 \pm 5 \% \mathrm{RH}$. The residual drug content values of ETD co-crystal stored at $4 \pm 2^{\circ} \mathrm{C}$ was found to be higher as compared with formulation stored at room temperature and $45 \pm 2^{\circ} \mathrm{C}$. So, it can be concluded that the optimized formulation was more stable at $4 \pm 2^{\circ} \mathrm{C}$ and tend to degrade faster at higher temperature. Thus, it is recommended that the formulation should be stored in a refrigerator for a longer shelf life (Table 5).

The enhanced potential of SN5 in decreasing the NO and cytokine levels could be due to enhanced solubility of the co crystals which could have the ability to penetrate the cells.

The pharmacodynamic (PD) and pharmacokinetic (PK) study was performed on albino wistar rat. Oral administration of co-crystal of ETD $(20 \mathrm{mg} / \mathrm{kg})$ showed enhanced therapeutic efficacy. The statistical result of one-way ANOVA indicated that group treatment differed significantly, the $F$ test value was found to be 5.325 which was greater than tabulated $p$ value $(p=3.10)$ which showed reduction in inflammation level in comparison with anti-inflammation control group. Paw of rat Group I (treated with $0.9 \% \mathrm{NaCl}), 1$ ) before induction of inflammation, 2) after induction of inflammation at $2 \mathrm{~h}$, revealed that inflammation 
remained up to $24 \mathrm{~h}$. Percent inhibition of inflammation was greater by co-crystal of ETD than by marketed formulation. Hence, $\mathrm{SN}-5$ was the better formulation than the marketed formulation. In $\mathrm{PK}, \mathrm{C}_{\max }$ of ETD and SN-5 was found to be $4.19 \mu \mathrm{g} / \mathrm{ml}$ and $9.12 \mu \mathrm{g} / \mathrm{ml}, t_{\max }$ of ETD and SN-5 was found to be 3.01 $\mathrm{h}$ and $4.01 \mathrm{~h}$. $\mathrm{C}_{\max }$ got increased in SN-5 than ETD and $\mathrm{t}_{\max }$ decreased in SN-5 than ETD. This indicated enhanced solubility and bioavailability. The $t_{1 / 2}$ of formulation increased upto $20.11 \mathrm{~h}$ demonstrating prolonged release.

\section{Conclusion}

The co-crystals were successfully prepared using different co-formers by neat grinding, solvent assisted grinding and solvent evaporation technique. These co-crystals were characterized by means of melting point, FTIR, SEM, DSC, and PXRD. These studies signified the formation of new crystalline phase due to physical or chemical interaction between drug and co-former. The solubility of the drug was found to increase due to co-crystal formation. The co-crystals formed with CA showed 6.15 folds increase in aqueous solubility and with TA showed 5.81 folds increase in aqueous solubility. The co-crystals formed with ETD-CA showed best aqueous solubility as well as best dissolution profile in comparison with other co-crystals. The formulation SN-5 was used for stability studies. The residual drug content values ETD co-crystal stored at $4 \pm 2^{\circ} \mathrm{C}$ was found to be higher as compared with formulation stored at room temperature and $45 \pm 2^{\circ} \mathrm{C}$. So, it can be concluded that the optimized formulation was more stable at $4 \pm$ $2^{\circ} \mathrm{C}$ and tended to degrade faster at higher temperature. The formulation SN5 displayed enhanced therapeutic efficacy as confirmed through reduced $\mathrm{NO}$ and cytokine levels as well as in vivo evaluation. The co-crystals were seen degrading more in the higher temperature $45 \pm 2^{\circ} \mathrm{C}$; this can be confirmed due the FTIR peaks and DSC. In PD, percent inhibition of inflammation is improved by co-crystal of ETD in comparison to that of the marketed formulation. In PK, $\mathrm{C}_{\max }$ was significantly increased in $\mathrm{SN}-5$ than ETD. Hence, the solubility and bioavailability of drug got improved after co-crystal formation.

\section{Declarations}

\section{Funding}

None.

\section{Conflict of interest}

The authors declare no conflicts of interest.

\section{Acknowledgements}

None

\section{Supportive/supplementary material}


Supplementary material is available on the publisher's website along with the published article.

\section{Ethics approval and consent to participate}

This protocol was reviewed and approved by the Institutional Animal Ethics Committee as per approval number 1451/PO/E/11/CPCSEA.

\section{Human and animal rights}

No human subjects were used in the present study. All experimental procedures involving animals were performed in accordance with protocols approved by the Institutional Animal Ethics Committee

\section{Consent for publication}

Not applicable.

\section{Availability of data and materials}

The authors confirm that the data supporting the findings of this study are available within the article.

\section{References}

1. Cirrpanli Y, Robineau C, Capan Y, Caliso S. Etodolac loaded poly (lactide-co-glycolide) nanoparticles: formulation and in vitro characterization. Hacettepe Univ J Faculty Pharm. 2009;29:105-14.

2. Tas C, Ozkan Y, Okyar A, Savaser A. In vitro and ex vivo permeation studies of etodolac from hydrophilic gels and effect of terpenes as enhancers. Drug Deliv. 2007;14:453-9.

3. Brocks DR, Jamali F. (1994). Etodolac clinical pharmacokinetics. Clinical pharmacokinetics 26, 259 74.

4. Dung PT, Trung TQ, Kim KH. Preparative resolution of etodolac enantiomers by preferential crystallization method. Arch Pharm Res. 2009;32:1425.

5. Inoue N, Nogawa M, Ito S, Tajima K, Kume S, Kyoi T. The enantiomers of etodolac, a racemic antiinflammatory agent, play different roles in efficacy and gastrointestinal safety. Biological Pharmaceutical Bulletin. 2011;34:655-9.

6. Barakat NS. (2006). Etodolac-liquid-filled dispersion into hard gelatin capsules: an approach to improve dissolution and stability of etodolac formulation. Drug development and industrial pharmacy 32, $865-76$.

7. Qiao N, Li M, Schlindwein W, Malek N, Davies A, Trappitt G. Pharmaceutical cocrystals: an overview. International journal of pharmaceutics. 2011;419:1-11.

8. Amidon GL, Lennernas H, Shah VP, Crison JR. (1995). A theoretical basis for a biopharmaceutic drug classification: the correlation of in vitro drug product dissolution and in vivo bioavailability. Pharmaceutical research 12, 413 - 20. 
9. Jayasankar A, Somwangthanaroj A, Shao ZJ, Rodriguez-Hornedo N. Cocrystal formation during cogrinding and storage is mediated by amorphous phase. Pharmaceutical research. 2006;23:238192.

10. Babu NJ, Nangia A. Solubility advantage of amorphous drugs and pharmaceutical cocrystals. Cryst Growth Des. 2011;11:2662-79.

11. Rodriguez-Hornedo N, Nehm SJ, Jayasankar A. (2006). Cocrystals: design, properties and formation mechanisms. Encyclopedia of pharmaceutical technology 3, 615-35.

12. Trask AV, Motherwell WDS, Jones W. Physical stability enhancement of theophylline via cocrystallization. International journal of pharmaceutics. 2006;320:114-23.

13. Aakeroy $C B$, Forbes $S$, Desper J. Using cocrystals to systematically modulate aqueous solubility and melting behavior of an anticancer drug. J Am Chem Soc. 2009;131:17048-9.

14. Childs SL, Hardcastle KI. Cocrystals of piroxicam with carboxylic acids. Cryst Growth Des. 2007;7:1291-304.

15. Trifiro F, Vaccari A. (1996). Comprehensive supramolecular chemistry. Comprehensive supramolecular chemistry 7.

16. Goud NR, Suresh K, Nangia A. (2013). Solubility and stability advantage of aceclofenac salts. Crystal Growth \& Design 13, $1590-601$.

17. Na Y-R, Yoon Y-N, Son D-I, Seok S-H. Cyclooxygenase-2 inhibition blocks M2 macrophage differentiation and suppresses metastasis in murine breast cancer model. PloS one. 2013;8:e63451.

18. Gervais F, Martel RR, Skamene E. (1984). The effect of the non-steroidal anti-inflammatory drug etodolac on macrophage migration in vitro and in vivo. Journal of immunopharmacology 6, $205-$ 14.

19. Chan CC, Boyce S, Brideau C, Ford-Hutchinson AW, Gordon R, et al. Pharmacology of a selective cyclooxygenase-2 inhibitor, L-745,337: a novel nonsteroidal anti-inflammatory agent with an ulcerogenic sparing effect in rat and nonhuman primate stomach. J Pharmacol Exp Ther. 1995;274:1531-7.

20. Singh N, Parashar P, Tripathi CB, Kanoujia J, Kaithwas G, Saraf SA. Oral delivery of allopurinol niosomes in treatment of gout in animal model. J Liposome Res. 2017;27:130-8.

21. Singh S, Parashar P, Kanoujia J, Singh I, Saha S, Saraf SA. Transdermal potential and anti-gout efficacy of Febuxostat from niosomal gel. Journal of Drug Delivery Science Technology. 2017;39:348-61.

22. Thakuria R, Delori A, Jones W, Lipert MP, Roy L, Rodriguez-Hornedo N. (2013). Pharmaceutical cocrystals and poorly soluble drugs. International journal of pharmaceutics 453, $101-25$.

\section{Figures}


(a)
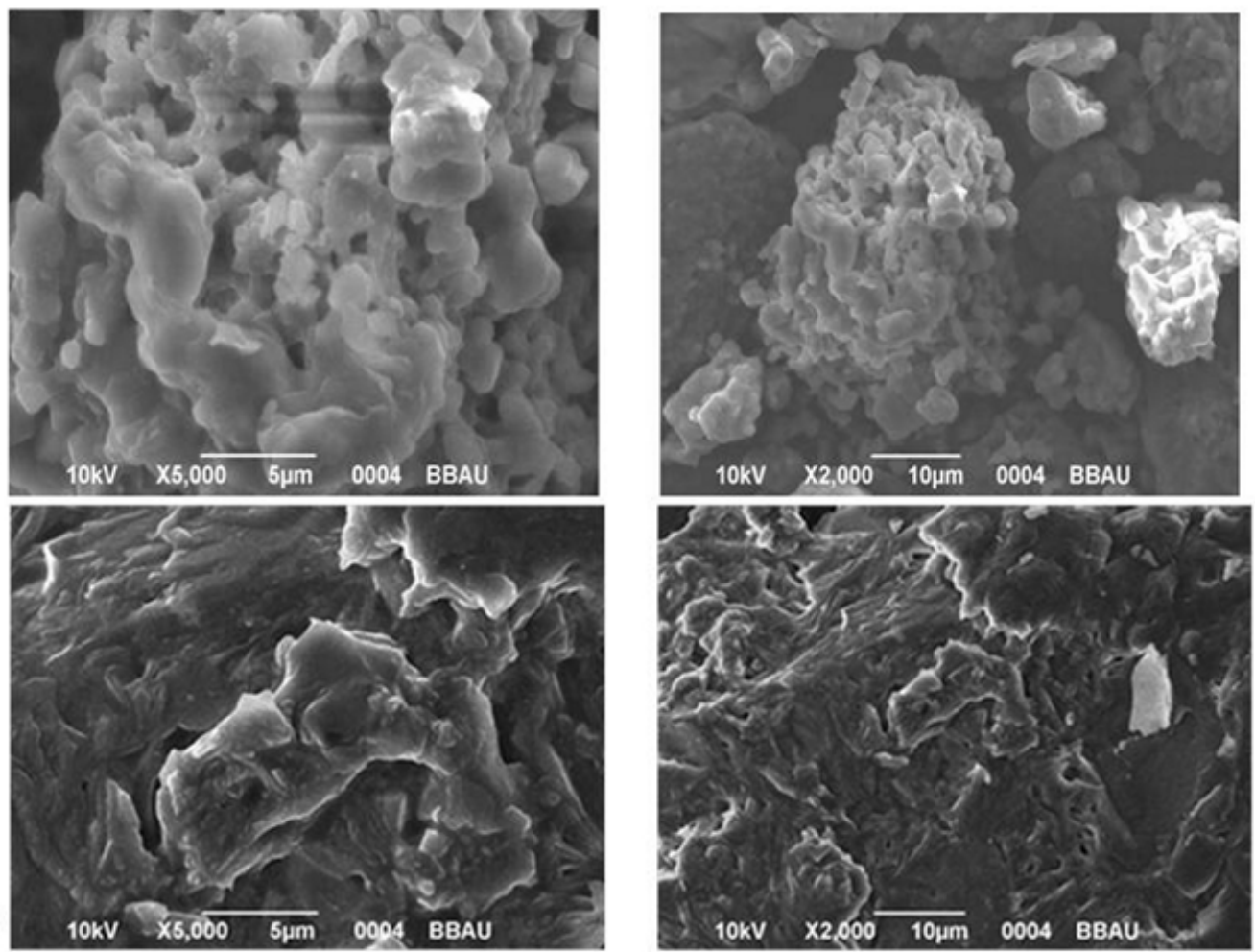

(b)
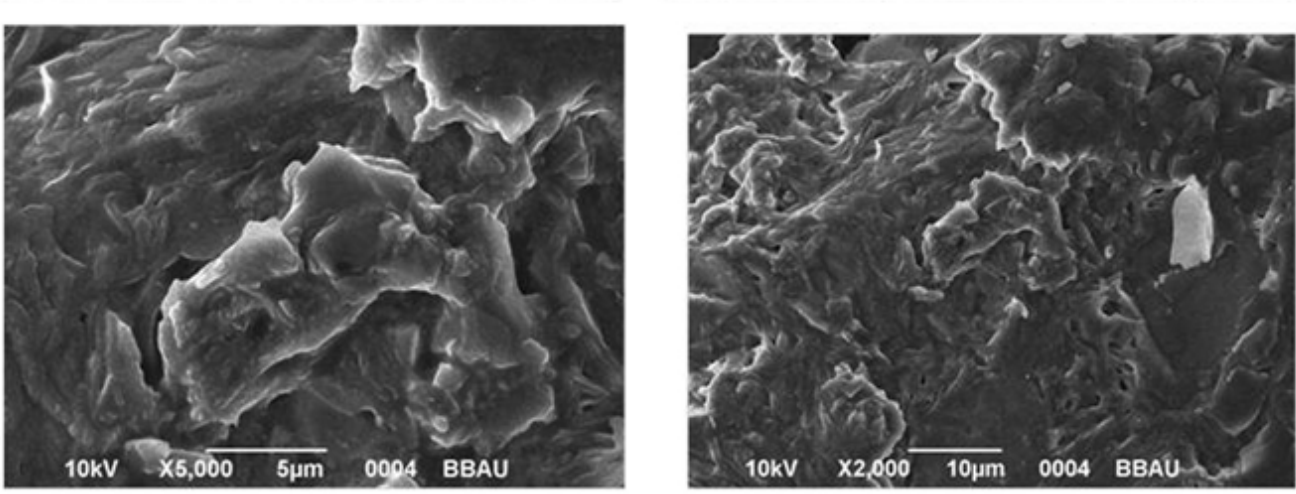

(c)
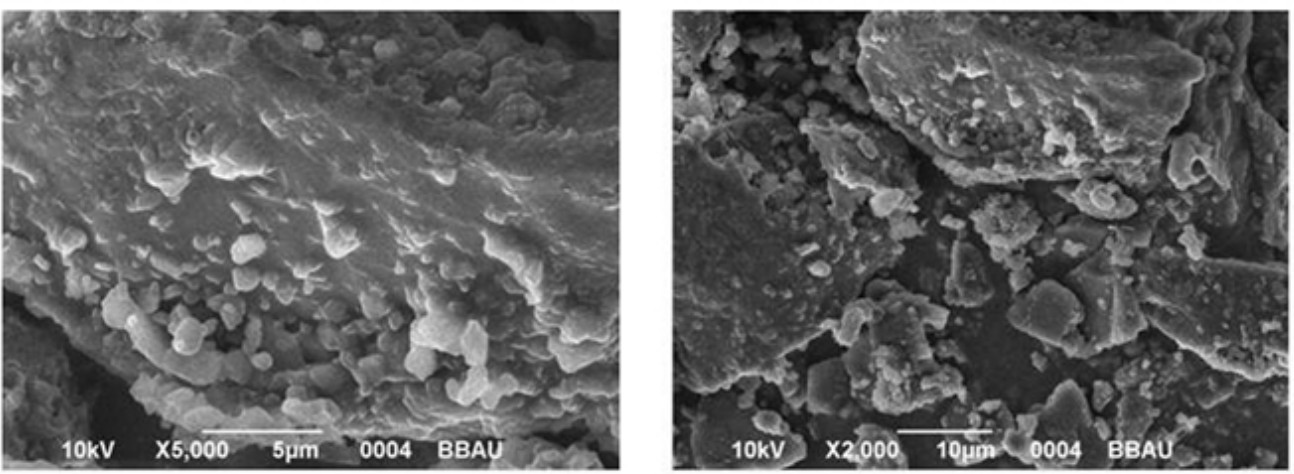

Figure 1

(a) SEM image at 5000X and 2000X, (a) ETD, (b) SN-3(ETD-CA), (c) SN-5(ETD-CA) (d) SN-9 (ETD-TA) 

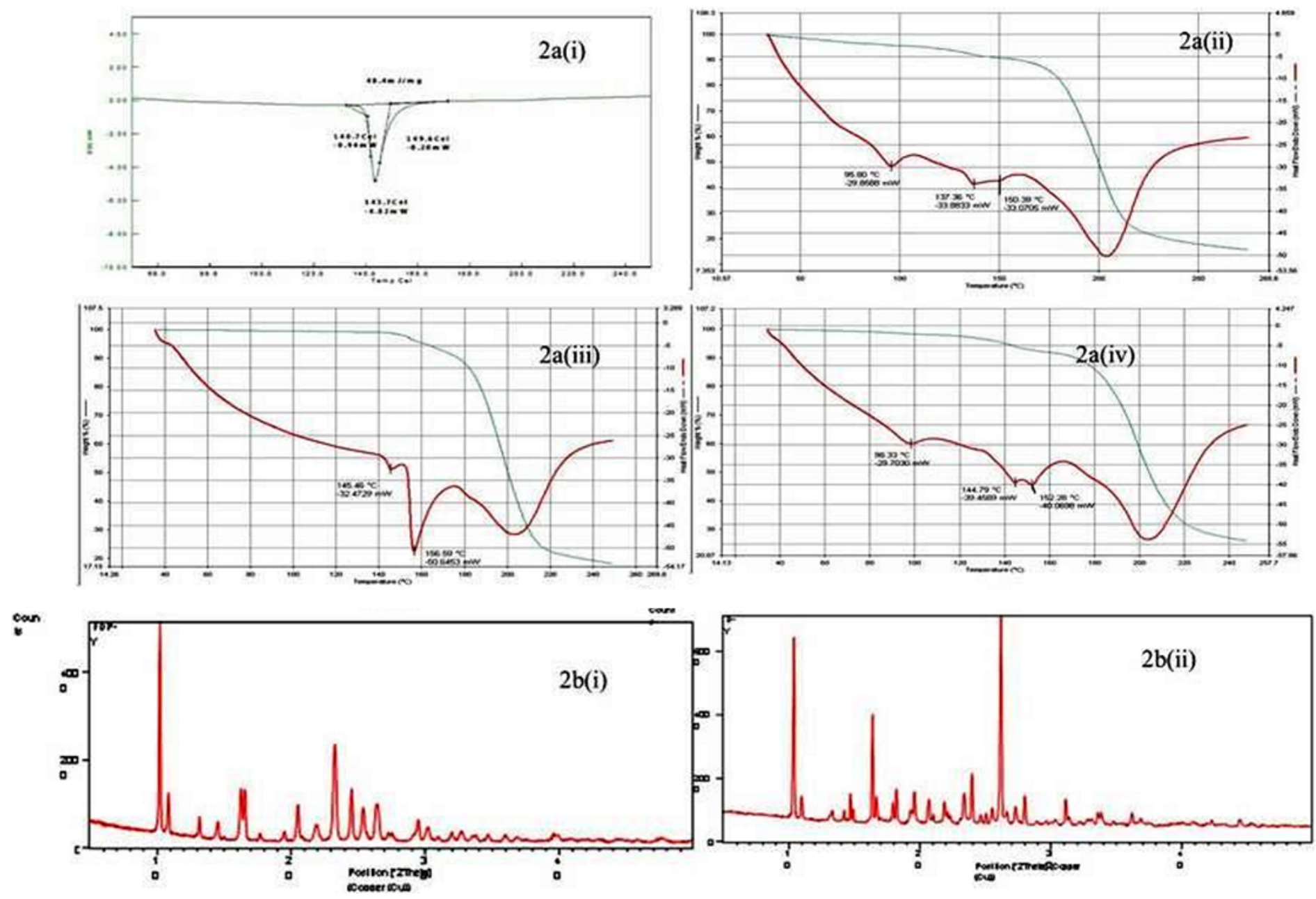

Figure 2

a (i). DSC thermogram of ETD a (ii). DSC thermogram of co-crystal SN-3 (ETD-CA) a (iii). DSC thermogram of co-crystal SN-5 (ETD-CA) a(iv). DSC thermogram of co-crystal SN-9 (ETD-TA) b(i). XRD pattern of pure drug Etodolac b(ii) XRD pattern of co-crystal SN-5 (ETD-CA)
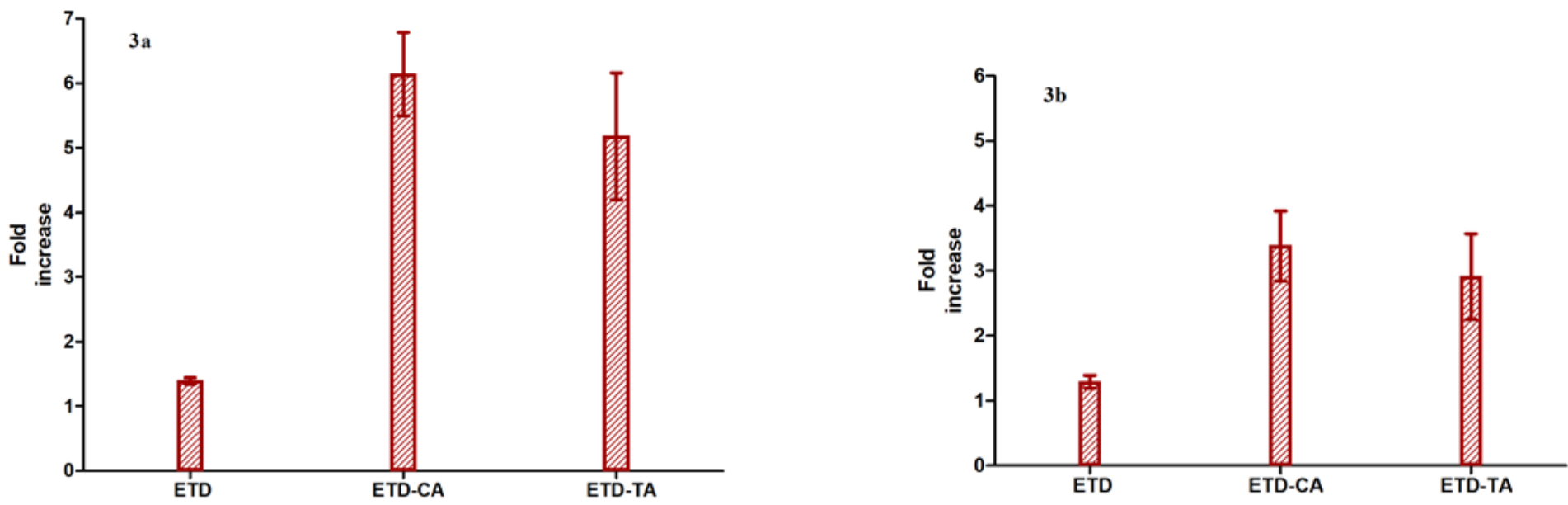

Figure 3 
Solubility of pure drug and its co-crystals in (a) distilled water (b) phosphate buffer ( $\mathrm{pH}$ 6.8)

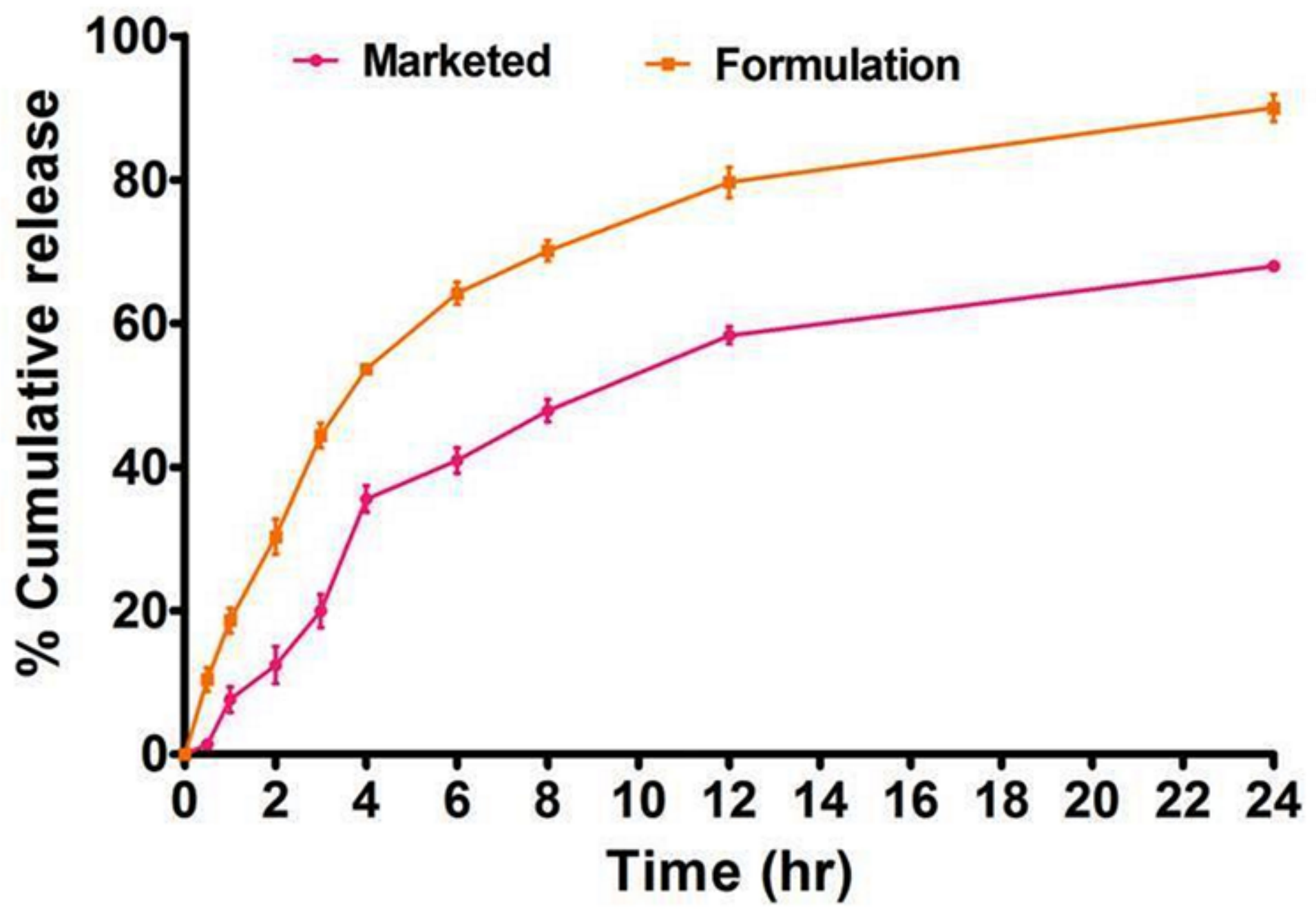

Figure 4

Percentage cumulative drug release of capsule (SN-5) vs marketed formulation in phosphate buffer $\mathrm{pH}$ 6.8 

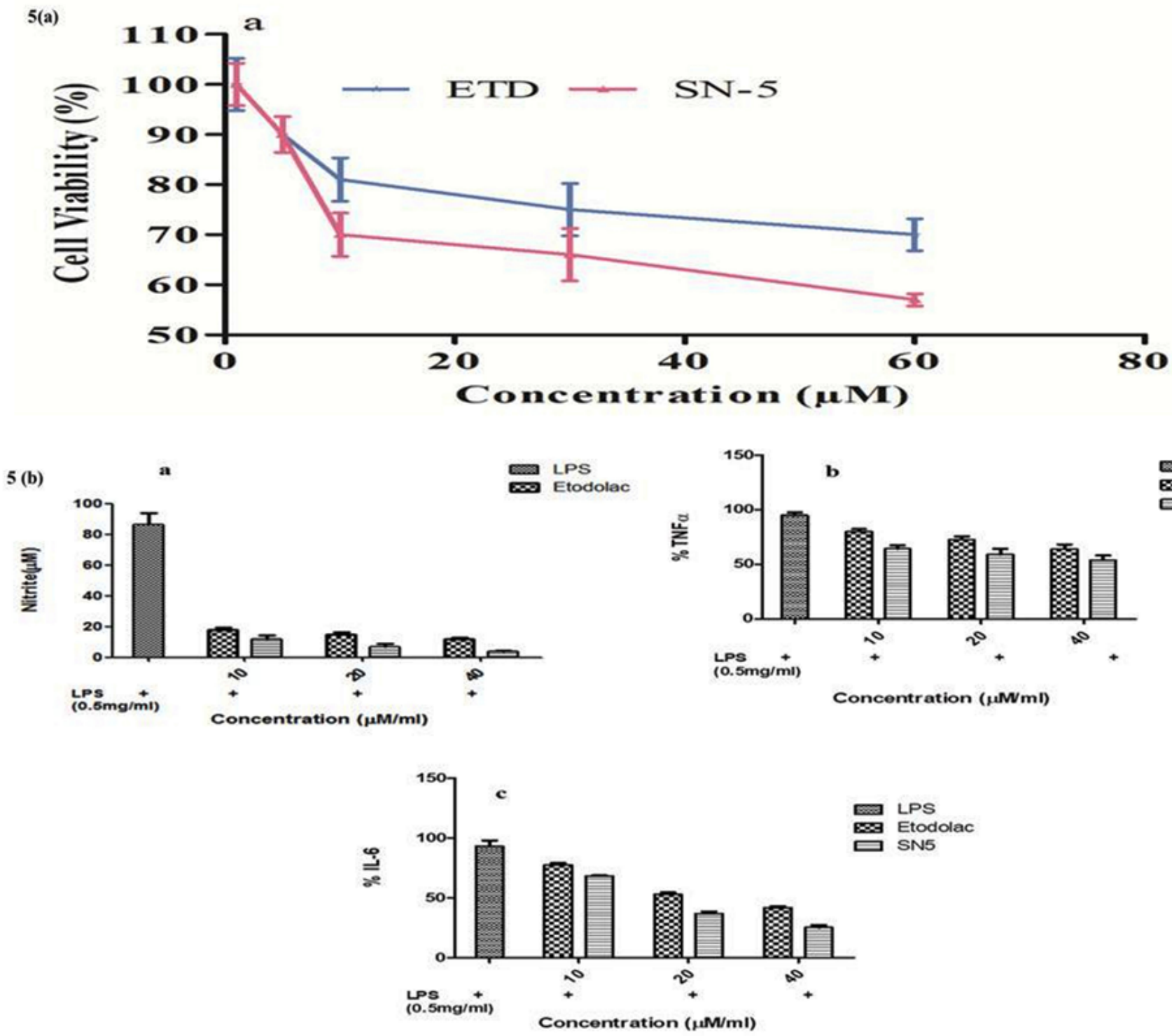

Figure 5

(a) Cytotoxicity evaluation of SN-5 and ETD on J774 macrophage cells (b) The effect of etodolac and SN5 on LPS-induced (A) nitric oxide concentration (B) TNF-a and (C) IL-6 release 


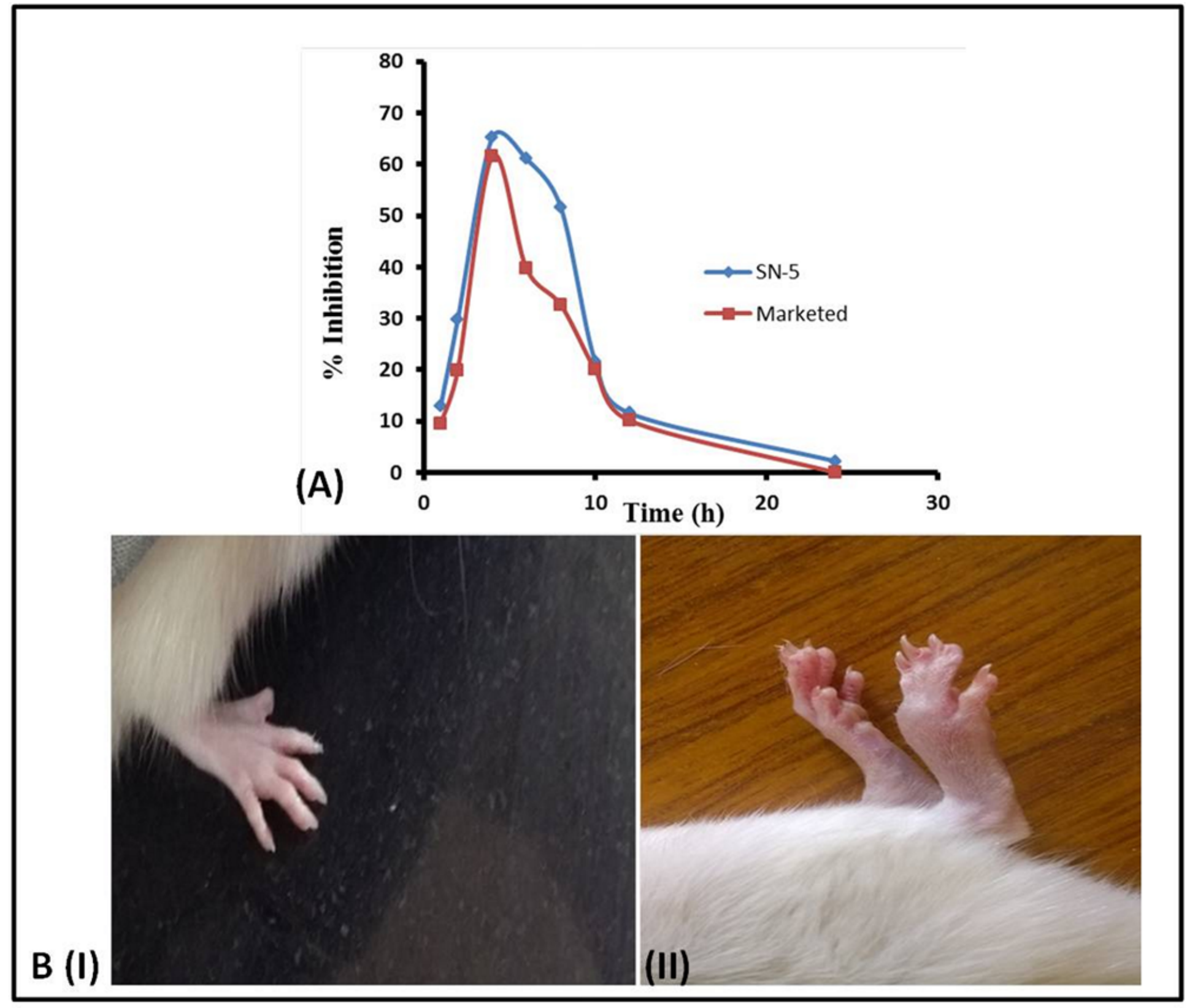

Figure 6

Inhibition in paw edema with respect to time, (B) inflammation in rat after injecting Carrageenan at $0 \mathrm{~h}$ (I) and at $2 \mathrm{~h}$ (II) (Comparison between normal and inflamed paw of rat)

\section{Supplementary Files}

This is a list of supplementary files associated with this preprint. Click to download.

- GraphicalAbstract.png

- SupplemntaryData.doc 